\title{
ASO Author Reflections: Use of Peritoneal Cancer Index (PCI) to Evaluate Carcinomatosis in Ovarian Cancer
}

\author{
Karin Stålberg, MD, PhD, and Björg Jónsdóttir, MD \\ Department of Women's and Children's Health, Uppsala University, Uppsala, Sweden
}

\section{PAST}

The peritoneal cancer index (PCI) was introduced by Paul Sugarbaker to describe peritoneal carcinomatosis, initially for colorectal cancer and mesothelioma. ${ }^{1}$ PCI illustrates the distribution and the volume of carcinomatosis. In colorectal cancer, PCI shows a linear relationship with overall survival ${ }^{2}$ and affects postoperative quality of life. ${ }^{3}$ It is not generally recommended to operate on patients with colorectal carcinomatosis with PCI over $20 .{ }^{4}$ Previous studies on PCI in ovarian cancer are few and heterogeneous, suggesting cutoffs for surgery from 10 to 25 , and since many of the studies were conducted, surgery has become more extensive. ${ }^{5,6}$

However, in most studies (both prospective and retrospective) on ovarian cancer, the FIGO stage is used to categorize the spread of the disease. The FIGO stage is quite a blunt tool with the majority of cases in stage IIIC, including patients with carcinomatosis ranging from a single peritoneal implant $\geq 2 \mathrm{~cm}$ in the upper abdomen to massive carcinomatosis. The assessment of PCI gives a more specific measurement and can be used both in preoperative imaging ${ }^{7}$ for deciding primary treatment (surgery or neoadjuvant chemotherapy) and in studies to compare populations.

(C) The Author(s) 2020

First Received: 14 May 2020;

Published Online: 28 May 2020

K. Stålberg, MD, PhD

e-mail: karin.stalberg@kbh.uu.se

\section{PRESENT}

The main aim of the present study ${ }^{8}$ was to find a PCI cutoff value for incomplete cytoreductive surgery (CRS) in patients with ovarian or fallopian tube cancer. Secondary aims were to identify reasons for open-close surgery and to compare surgical complications in relation to tumor burden. In the study cohort of 167 women, we can demonstrate that perioperative PCI was an excellent predictor of incomplete CRS and surgical complications. We identified two cutoff values for PCI: in patients with PCI $>24$, the frequency of incomplete CRS was $32.7 \%$, and $27 \%$ had a major complication; the corresponding figures for PCI > 33 were $71.4 \%$ incomplete CRS and $43 \%$ major complications. In 14 patients (total PCI 27-37), the carcinomatosis was considered inoperable and the abdomen was closed; the reason was massive infiltration on the small bowel in all cases.

\section{FUTURE}

Based on our results ${ }^{8}$ and literature, we suggest that neoadjuvant chemotherapy should be considered when PCI $>24$, especially in fragile patients, to achieve optimal surgical outcome and minimize major complications. We recommend that PCI should be used as a standard parameter in clinical management of advanced gynecologic cancers and included in registers and research. Our findings support further studies on PCI in preoperative imaging as more accurate knowledge of tumor load could enhance patient selection before surgery. Our findings strengthen that the focus on preoperative radiology might be evaluation of total tumor burden, since this is strongly associated with operability.

ACKNOWLEDGMENT Open access funding provided by Uppsala University. 
OPEN ACCESS This article is licensed under a Creative Commons Attribution 4.0 International License, which permits use, sharing, adaptation, distribution and reproduction in any medium or format, as long as you give appropriate credit to the original author(s) and the source, provide a link to the Creative Commons licence, and indicate if changes were made. The images or other third party material in this article are included in the article's Creative Commons licence, unless indicated otherwise in a credit line to the material. If material is not included in the article's Creative Commons licence and your intended use is not permitted by statutory regulation or exceeds the permitted use, you will need to obtain permission directly from the copyright holder. To view a copy of this licence, visit http://creativecommons. org/licenses/by/4.0/.

\section{REFERENCES}

1. Jacquet P, Sugarbaker PH. Clinical research methodologies in diagnosis and staging of patients with peritoneal carcinomatosis. In: Sugarbaker PH, editor. Peritoneal Carcinomatosis: Principles of Management. Boston, MA: Springer; 1996. p. 359-74.

2. Faron M, Macovei R, Goere D, Honore C, Benhaim L, Elias D. Linear relationship of peritoneal cancer index and survival in patients with peritoneal metastases from colorectal cancer. Ann Surg Oncol. 2016;23(1):114-9.

3. Steffens D, Koh C, Ansari N, Solomon MJ, Brown K, McBride K, et al. Quality of life after cytoreductive surgery and hyperthermic intraperitoneal chemotherapy: early results from a prospective cohort study of 115 patients. Ann Surg Oncol. 2020;27:1875-6.

4. Simkens GA, Rovers KP, Nienhuijs SW, de Hingh IH. Patient selection for cytoreductive surgery and HIPEC for the treatment of peritoneal metastases from colorectal cancer. Cancer Manag Res. 2017;9:259-66.

5. Llueca A, Serra A, Rivadulla I, Gomez L, Escrig J, MUAPOS Working Group. Prediction of suboptimal cytoreductive surgery in patients with advanced ovarian cancer based on preoperative and intraoperative determination of the peritoneal carcinomatosis index. World J Surg Oncol. 2018;16(1):37.

6. Lampe B, Kroll N, Piso P, Forner DM, Mallmann P. Prognostic significance of Sugarbaker's peritoneal cancer index for the operability of ovarian carcinoma. Int $J$ Gynecol Cancer. 2015;25(1):135-44.

7. Low RN, Barone RM, Lucero J. Comparison of MRI and CT for predicting the peritoneal cancer index (PCI) preoperatively in patients being considered for cytoreductive surgical procedures. Ann Surg Oncol. 2015;22(5):1708-15.

8. Jónsdóttir B, Lomnytska M, Sundström Poromaa I, Silins I, Stålberg K. Peritoneal cancer index is a strong predictor of incomplete cytoreductive surgery in ovarian cancer. Ann Surg Oncol. 2020. https://doi.org/10.1245/s10434-020-08649-6.

Publisher's Note Springer Nature remains neutral with regard to jurisdictional claims in published maps and institutional affiliations. 